\title{
Hepatoma-Derived Growth Factor Secreted from Mesenchymal Stem Cells Reduces Myocardial Ischemia-Reperfusion Injury
}

\author{
Yu Zhou, ${ }^{1,2}$ Panpan Chen, ${ }^{1,2}$ Qingnian Liu,, ${ }^{1,2}$ Yingchao Wang, ${ }^{1,2}$ Ling Zhang, ${ }^{1,2}$ \\ Rongrong Wu, ${ }^{1,2}$ Jinghai Chen, ${ }^{1,2}$ Hong Yu, ${ }^{1,2}$ Wei Zhu, ${ }^{1,2}$ Xinyang Hu, ${ }^{1,2}$ \\ and Jian-An Wang ${ }^{1,2}$ \\ ${ }^{1}$ Department of Cardiology, Second Affiliated Hospital of Zhejiang University School of Medicine, 88 Jiefang Rd, \\ Hangzhou 310009, China \\ ${ }^{2}$ Cardiovascular Key Laboratory of Zhejiang Province, 88 Jiefang Rd, Hangzhou 310009, China
}

Correspondence should be addressed to Jian-An Wang; jian_an_wang@yahoo.com

Received 25 May 2017; Accepted 4 October 2017; Published 14 November 2017

Academic Editor: Yanfang Chen

Copyright (c) $2017 \mathrm{Yu}$ Zhou et al. This is an open access article distributed under the Creative Commons Attribution License, which permits unrestricted use, distribution, and reproduction in any medium, provided the original work is properly cited.

\begin{abstract}
Objectives. The present study aimed to explore the major factors that account for the beneficial effects of mesenchymal stem cells (MSCs). Methods. Using isobaric tags for relative and absolute quantitation method, hepatoma-derived growth factor (HDGF) was identified as an important factor secreted by MSCs, but not by cardiac fibroblasts (CFs). The protective effects of conditioned medium (CdM) from MSCs or CFs were tested by using either H9C2 cells that were exposed by hypoxia-reoxygenation $(\mathrm{H} / \mathrm{R})$ insult or an in vivo mouse model of myocardial ischemia-reperfusion. Results. Compared to CF-CdM, MSC-CdM conferred protection against reperfusion injury. CdM obtained from MSCs that were treated with HDGF-targeted shRNA failed to offer any protection in vitro. In addition, administration of recombinant HDGF alone recapitulated the beneficial effects of MSC-CdM, which was associated with increased protein kinase C epsilon (PKCE) phosphorylation, enhanced mitochondria aldehyde dehydrogenase family 2 activity, and decreased 4-hydroxy-2-nonenal accumulation. A significant decrease in infarct size and ameliorated cardiac dysfunction was achieved by administration of HDGF in wild-type mice, which was absent in PKCe dominant negative mice, indicating the essential roles of PKCe in HDGF-mediated protection. Conclusions. HDGF secreted from MSCs plays a key role in the protection against reperfusion injury through $\mathrm{PKC} \varepsilon$ activation.
\end{abstract}

\section{Introduction}

Ischemic heart diseases, such as myocardial infarction, continue to be one of the leading causes of mortality and morbidity worldwide [1]. Although the application of thrombolysis and vascular intervention salvages myocardium and significantly improves clinical outcomes, reperfusion results in myocardial injury. On reperfusion, the generation of reactive oxygen species (ROS), rapid reintroduction of adenosine triphosphate in the presence of elevated $\left[\mathrm{Ca}^{2+}\right]_{\mathrm{i}}$, and induction of the mitochondrial permeability transition lead to hypercontracture as well as apoptotic and oncotic cell death [2]. In addition, reperfusion induces accumulation of 4-hydroxy-2-nonenal (4-HNE) [3], a production of lipid peroxidation [4] that contributes to myocyte injury [5]. However, therapeutic agents to prevent these injuries remain unavailable so far. Therefore, effective cell protection after reperfusion is still an unmet clinical need.

Bone marrow-derived mesenchymal stem cells (MSCs) are one of the most rigorously studied stem cell populations [6], which are now undergoing phase II clinical trials for treating ischemic heart diseases. The low cardiac differential and retention rate of MSCs suggests that the secretion of paracrine factors [7], rather than regenerating the functional myocytes, confers cardioprotection by MSCs. Our previous work [8-11] on rodent and primate models demonstrated 
that MSC therapy enhanced the survival of cardiomyocytes, reduced myocardial fibrosis, and improved angiogenesis through paracrine effects, in which the factors secreted from MSCs, including leptin [12], miR-211 [8], and heparinase [9], played an important role in cardiac protection. Of note, evidence has been put forward showing that treatment using MSC secretions is sufficient to reduce reperfusioninduced myocardial apoptosis and oxidative stress in both rodent and large animal models [13, 14]. However, the factors that contribute to the beneficial effects of MSCs have not been defined.

In the present study, by isobaric tags for relative and absolute quantitation (iTRAQ) secretomic analysis of either MSCs or cardiac fibroblasts (CFs), we have identified that hepatoma-derived growth factor (HDGF) was one of those factors secreted by MSCs and can confer protection against reperfusion-induced cardiomyocyte death. Treatment of HDGF recombinant protein reduces apoptosis and oxidative stress in vitro which in turn can decrease myocardial infarct size in an in vivo mouse model in a protein kinase $\mathrm{C}$ epsilon(PKC $\left.\varepsilon^{-}\right)$dependent fashion.

\section{Materials and Methods}

2.1. Animals. For detailed methods, please refer to the Supplementary Material available online at https://doi. org/10.1155/2017/1096980. Wild-type (WT) littermates and $\mathrm{PKC} \varepsilon$-dominant negative $(\mathrm{PKC} \varepsilon$-DN) mice were kindly provided from Professor Peipei Ping [15]. All animal studies were performed with the approval of the Institutional Animal Care and Use Committee, Zhejiang University and according to the Chinese Guideline for Laboratory Animal Care and Use.

2.2. Conditioned Medium Preparation. Mice MSCs isolated from 4- to 5-week-old wild-type (WT) mouse bone marrow were examined for the characteristic surface antigen profile by flow cytometry and cultured as described previously [12]. Cardiac fibroblasts were isolated from WT mice as described previously [11]. MSCs or fibroblasts of $80 \%$ confluence were washed with PBS and cultured in serum-free medium for $24 \mathrm{~h}$. The conditioned medium was then centrifugated and concentrated 25 -fold less of the original volume using $3 \mathrm{kDa}$ molecular weight cutoff ultrafiltration membranes (Millipore, MA, USA). The concentrated medium was desalted and diluted to $0.5 \mathrm{mg} / \mathrm{mL}$ for tail vein injection.

2.3. Ischemia-Reperfusion Models and Hemodynamic Measurement. Mice were anesthetized with intraperitoneal injection of pentobarbital sodium $(60 \mathrm{mg} / \mathrm{kg})$ and then subjected to the left anterior descending (LAD) coronary artery ligation including silicon tubing on top of the coronary artery with an 8-0 Prolene suture. Fifteen minutes before occlusion, $0.2 \mathrm{~mL}$ of vehicle or conditioned medium derived from MSCs (MSC-CdM) or CFs (CF-CdM) was injected via tail vein. After $45 \mathrm{~min}$ of ischemia, the silicon tubing was removed to achieve reperfusion. The Evan's blue and 2,3,5-triphenyltetrazolium chloride staining were performed on cardiac tissue sections to identify the area at risk and the infarct area.
Hemodynamic assessment was taken at $24 \mathrm{~h}$ reperfusion by a $1.4 \mathrm{~F}$ pressure catheter inserted through the right carotid artery into the left ventricle (LV). The transducer was connected to the PowerLab system (AD Instruments, Castle Hill, Australia). LV pressure and LV maximum $\pm \mathrm{dp} / \mathrm{dt}$ were recorded and averaged from 15 beats.

2.4. Western Blot Analysis. Culture media were precipitated with trichloroacetic acid ( $1: 100$, vol/vol, overnight incubation at $\left.-20^{\circ} \mathrm{C}\right)$. The precipitates were rinsed with acetone, prior to be resuspended into lysis buffer. Proteins extracted from cells or heart tissues ( $40 \mu \mathrm{g}$ protein for each sample) were electrophoresed on a SDS-PAGE and transferred onto a PVDF membranes (Bio-Rad) and incubated with primary antibodies against phosphorylated $\mathrm{PKC} \varepsilon(1: 500$, Santa Cruz, CA, USA), PKC $\varepsilon$, cleaved caspase-3, $\beta$-actin ( $1: 1000$, all from Cell Signaling Technology, Danvers, MA, USA), or 4HNE (1:500) (both from Abcam, Cambridge, MA, USA). Then, membranes were incubated with HRP-conjugated secondary antibodies and exposed with the Chemiluminescence Detection Kit (Millipore).

2.5. Mitochondrial Aldehyde Dehydrogenase Family 2 (ALDH2) Activity Assay. Mitochondria were isolated using a mitochondrial protein extraction kit (Keygentec, Nanjing, China) according to the instruction supplied by the manufacturer. The ALDH2 activity of mitochondria from cardiomyocytes was measured using a mito-ALDH2 activity kit (Abcam) by a SpectraMax 340PC384 Microplate Reader (Molecular Devices, LLC., CA, USA).

2.6. Transferase dUTP Nick End Labeling (TUNEL) Assay and Immunofluorescence Staining. Frozen heart tissue sections were fixed and permeabilized before incubated with primary antibodies and respective secondary antibodies. The apoptosis of cells was detected in situ with TUNEL (Roche Applied Science, IN, USA). cTnI antibody (1:200 Abcam) was applied as a cardiomyocyte marker with DAPI counterstaining.

2.7. Flow Cytometry Analysis of Cell Apoptosis. The Annexin V-FITC/PI Apoptosis Detection Kit was used to evaluate apoptosis of cells. After rinsed with cold PBS, cells were resuspended in $200 \mu \mathrm{l}$ of binding buffer. Annexin V solution was added to the cells and incubated for $30 \mathrm{~min}$ at $4^{\circ} \mathrm{C}$. The cells were then incubated with $5 \mathrm{ml}$ propidium iodide (PI) and immediately analyzed with a FACScan. Ten thousand events were acquired on a FACSC-LSR (BectonDickinson, San Jose, CA) and analyzed with CellQuest (Becton-Dickinson) software.

2.8. Lentivirus Construction and Infection. Construction of the recombinant lentivirus with HDGF was performed by the Genechem Company. For MSC infection, cells were seeded at a density of $1 \times 10^{5}$ cells in a six-well plate and infected with lentiviral vectors with $10 \mathrm{mg} / \mathrm{ml}$ polybrene (Millipore, Boston, MA, USA). At 12 hour postinfection, the medium was replaced. Forty-eight hours later, the transfected cells were cultured in a $5 \% \quad \mathrm{CO}_{2}$-humidified incubator at $37^{\circ} \mathrm{C}$. 
2.9. Quantitative Polymerase Chain Reaction ( $q P C R$ ) Analysis. Primers for amplification of mouse HDGF genes were used to determine the expression of HDGF in fibroblasts and MSCs. The amplification program consisted of initial denaturation at $95^{\circ} \mathrm{C}$ for $10 \mathrm{~min}$ followed by 40 cycles from $92^{\circ} \mathrm{C}$ for $15 \mathrm{~s}$, annealing at $60^{\circ} \mathrm{C}$ for $30 \mathrm{~s}$ and extension at $72^{\circ} \mathrm{C}$ for $15 \mathrm{~s}$. The relative expression levels of each gene were normalized to $\beta$-actin using the 2 $\Delta \Delta \mathrm{Ct}$ method.

2.10. Protein Digestion and ITRAQ Labeling. For each sample, protein was digested and the peptide mixture was labeled using chemicals from the iTRAQ reagent kit (Applied Biosystems, California, USA). Disulfide bonds were reduced in $5 \mathrm{mM}$ Tris-(2-carboxyethy) phosphine (TCEP) followed by blocking cysteine residues in $10 \mathrm{mM}$ methyl methanethiosulfonate (MMTS), before digestion with sequence-grade modified trypsin (Promega, Madison, WI, USA). For labeling, each iTRAQ reagent was dissolved in isopropanol and added to the respective peptide mixture. The labeled samples were combined and dried.

2.11. High $p H$ Reverse Phase Separation. The peptide mixture was fractionated by high $\mathrm{pH}$ separation using the AQUITY UPLC system (Waters Corporation, Milford, MA, USA) connected to a reverse phase column(ACQUITY UPLC Peptide C18 column, $2.1 \mathrm{~mm} \times 150 \mathrm{~mm}, 1.7 \mu \mathrm{m}, 130 \AA$, Waters Corporation, Milford, MA, USA). High pH separation was performed using a linear gradient. The column was reequilibrated at initial conditions and the column flow rate was maintained at $600 \mu \mathrm{L} / \mathrm{min}$. Collected fractions were dried in a vacuum concentrator for the next step.

2.12. Low $p H$ Nano-HPLC-MS/MS Analysis. The mixed peptides were separated by nano-HPLC (Eksigent Technologies, Dublin, CA, USA) on the secondary RP analytical column (Eksigent, C18, $3 \mu \mathrm{m}, 150 \mathrm{~mm} \times 75 \mu \mathrm{m}$ ). Peptides were subsequently eluted using the following gradient conditions with phase B ( $98 \% \mathrm{ACN}$ with $0.1 \%$ formic acid) from 5 to $45 \% \mathrm{~B}$ (5-70 $\mathrm{min})$, and total flow rate was maintained at $300 \mathrm{~nL} / \mathrm{min}$. Electrospray voltage of $2.3 \mathrm{kV}$ versus the inlet of the mass spectrometer was used.

Triple TOF 4600 mass spectrometer was operated in the data-dependent mode to switch automatically between MS and MS/MS acquisition. MS spectra were acquired across the mass range of $350-1250 \mathrm{~m} / \mathrm{z}$ in high resolution mode using $250 \mathrm{~ms}$ accumulation time per spectrum. Tandem mass spectral scanned from $100-1250 \mathrm{~m} / \mathrm{z}$ in high sensitivity mode with rolling collision energy. The 20 most intense precursors were selected for fragmentation per cycle with dynamic exclusion time of $9 \mathrm{~s}$.

2.13. Statistical Analysis. All data are expressed as mean \pm SEM and analyzed by SPSS 17 using two-tailed Student's $t$-test between two groups or one-way analysis of variance (ANOVA) when three or more groups were compared. $P$ value less than 0.05 was considered as statistical significance.

\section{Results}

3.1. MSC-CdM but Not CF-CdM Induced Myocardial Protection against Reperfusion Injury. To compare the effects of MSC-CdM and CF-CdM on cardiac reperfusion injury, mice were intravenously treated with vehicle, MSC-CdM, or CF-CdM $15 \mathrm{~min}$ before occlusion of the LAD coronary artery. These mice were then subjected to $45 \mathrm{~min}$ of myocardial ischemia followed by $24 \mathrm{~h}$ of reperfusion. The area at risk was not different among the 3 experimental groups, but systemic delivery of MSC-CdM significantly reduced the infarct area/area at risk (I/AAR) and infarct area/left ventricular $(\mathrm{I} / \mathrm{LV})$ ratio by $24.6 \%$ and $25.6 \%(P<0.05)$, respectively, compared with infarcted mice injected with vehicle (Figure 1(a)). In contrast, CF-CdM did not significantly affect the infarct size, showing a similar I/AAR to that in the control mice.

The decreased infarct size in the MSC-CdM group was accompanied by improved functional recovery. Compared with the vehicle group, values for maximal left-ventricular pressure $\left(+\mathrm{dp} / \mathrm{dt}_{\max }\right)$ and minimal left-ventricular pressure $\left(-\mathrm{dp} / \mathrm{dt}_{\max }\right)$ measured at $24 \mathrm{~h}$ reperfusion were both significantly improved $(P<0.05)$ in MSC-CdM treated mice, which were, however, not observed $(P>0.05)$ in CF-CdMtreated mice (Figure 1(b)). In parallel, LV end-diastolic pressure (LVEDP) was not affected by MSC-CdM, indicating that the increase of $+\mathrm{dp} / \mathrm{dt}_{\max }$ is not due to altered preload (Supplementary Table 1). As Tau, an index of globe leftventricular relaxation, was not changed by MSC-CdM, the improvement of $-\mathrm{dp} / \mathrm{dt}_{\max }$ may have reflected the higher $+\mathrm{dp} / \mathrm{dt}_{\max }$ in this group.

The extent of apoptosis at $24 \mathrm{~h}$ reperfusion was assessed by TUNEL staining (Figure 1(c)). MSC-CdMtreated mice had significantly decreased TUNEL positive myocytes $(P<0.05)$ in the peri-infarct area of the heart compared with controls. However, CF-CdM did not decrease the percentage of apoptotic cells after reperfusion. Similarly, isolated myocytes treated with MSC-CdM exhibited enhanced contractile performance (Supplementary Fig. 1A) and upregulated calcium transient amplitude (Supplementary Fig. 1B) at $2 \mathrm{~h}$ reoxygenation following $4 \mathrm{~h}$ of hypoxia, all of which were absent in CF-CdM treated cardiomyocytes.

3.2. Proteomic Profiles of Secreted Protein in MSC-CdM and CF-CdM and Highly Secreted HDGF from MSCs. To identify the specific paracrine factors that were responsible for the beneficial effects of MSC-CdM, the iTRAQlabeled conditioned media protein samples of MSCs and CFs were analyzed. A total of 1787 proteins with at least 95\% confidence were identified in the conditioned medium, among which 1595 proteins had quantification information (Supplementary Table S3). The subcellular localization information of all the identified proteins was annotated by Gene Ontology. As a result, a total of 861 proteins were assigned as extracellular (Figure 2(a)), of which 55 proteins were secreted selectively at higher level in MSCCdM (>2-fold), while other 53 proteins were found highly secreted in CF-CdM ( $>2$-fold). Functional classification and an enrichment analysis based on molecular functions 

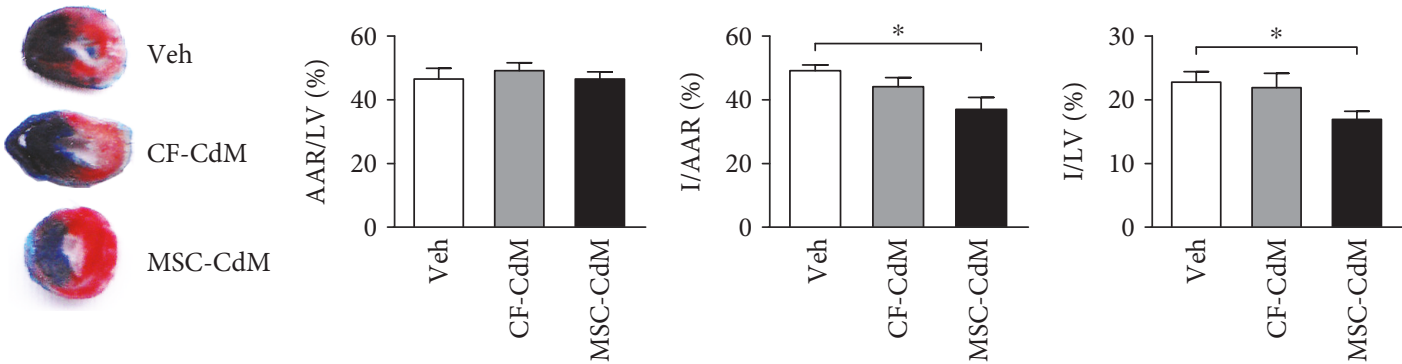

(a)
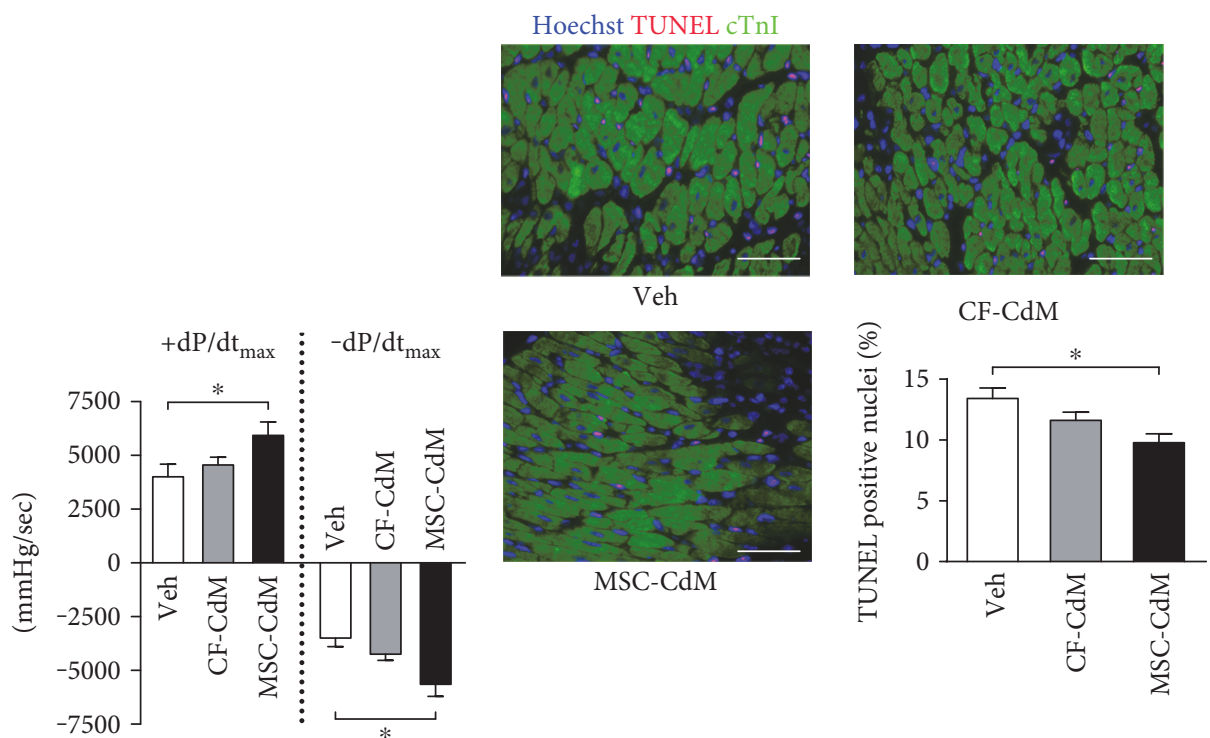

(b)

(c)

FIgURE 1: MSC-CdM reduce cardiac reperfusion injury. Wild-type mice were given $5 \mathrm{mg} / \mathrm{kg}$ CF-CdM, $5 \mathrm{mg} / \mathrm{kg}$ MSC-CdM, or vehicle i.v. $15 \mathrm{~min}$ before $45 \mathrm{~min}$ of ischemia. MSC-CdM: conditioned medium derived from MSC; CF-CdM: conditioned medium derived from cardiac fibroblasts. (a) Ratio of area at risk (AAR) to left ventricular (LV) area, ratio of infarct size (I) to AAR, and ratio of infarct size to $\mathrm{LV}$ after $24 \mathrm{~h}$ of reperfusion. Data represent mean \pm standard error of mean (SEM) of values from five mice. (b) The maximum rates of rise and decline of left-ventricular pressure $\left(+\mathrm{dp} / \mathrm{dt}_{\max }\right.$ and $\left.-\mathrm{dp} / \mathrm{dt}_{\max }\right)$ assessed at $24 \mathrm{~h}$ reperfusion. Data are mean $\pm \mathrm{SEM}$ of values from six mice. (c) TUNEL staining at $24 \mathrm{~h}$ reperfusion; apoptotic nuclei were stained (red), and cardiomyocytes were detected by cardiac troponin I staining (green). Bar $=50 \mu \mathrm{M}$. Data are mean \pm SEM of values from three hearts per group, with at least 3000 nuclei examined per heart. ${ }^{*} P<0.05$.

and biological processes revealed that these 108 differentially secreted proteins fell into many functional categories. We found that the number of proteins varied greatly for the different categories (Supplementary Fig. S2). Compared to CFs, MSCs secreted more proteins that were involved in the categories of "cellular process," "metabolic process," and "developmental process." In addition, MSC$\mathrm{CdM}$ contained more secreted proteins that were related to catalytic activity.

Among the list of 55 proteins specifically highly secreted by MSCs (Table 1), HDGF was selected for further study because this candidate could relay paracrine communication between MSCs and myocytes, as well as exhibit antiapoptosis and proliferation effects [16-19]. To validate that HDGF was secreted by MSCs, RT-qPCR was performed to detect the expression level of HDGF in MSCs and fibroblasts. The mRNA abundance of HDGF in MSCs was significantly higher compared with that in fibroblasts $(P<0.05)$ (Figure 2(b)). These data were consistent with immunoblotting results which showed that HDGF was highly selectively expressed in MSC-CdM with high density (Figure 2(c)). Thus, our data provided strong evidence that HDGF was highly secreted by MSCs.

3.3. HDGF Contributed to the Protective Effects of MSC-CdM. To test whether HDGF was involved in protective effects of MSC-CdM, we first used lentiviral shRNA to knockdown HDGF in MSCs and investigated apoptosis in heart-derived $\mathrm{H} 9 \mathrm{C} 2$ cells subjected to $4 \mathrm{~h}$ of reoxygenation following $9 \mathrm{~h}$ of hypoxia. PI-Annexin $\mathrm{V}$ double staining was used to identify the prevention effects of MSC$\mathrm{CdM}$ (Figure 3(a)). Conditioned medium derived from MSCs that transfected with empty vector (MSC ${ }^{\text {null }}$ ) reduced population of PI-Annexin V double positive cells 


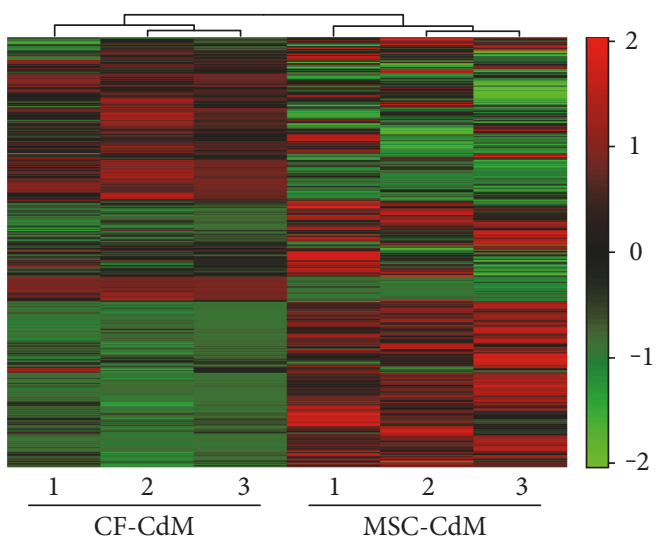

(a)

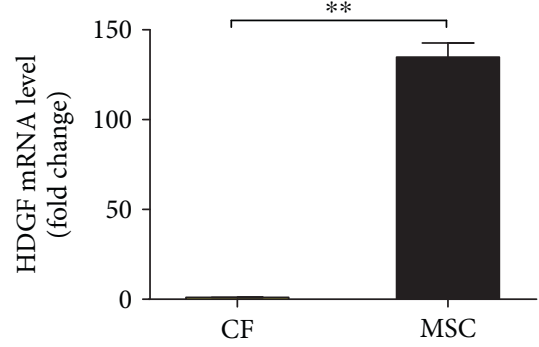

(b)

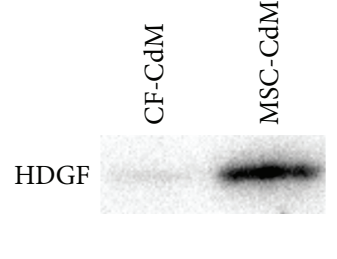

(c)

FIGURE 2: Secretome patterns and different HDGF expression between MSCs and fibroblasts. (a) iTRAQ analysis was applied and 1596 proteins were identified. Hierarchical clustering displayed as a heatmap. Red indicates an increase in expression, and green indicates decreases in expression compared with fibroblasts. (b) HDGF mRNA levels of MSCs and fibroblasts were assessed by RT-qPCR. Data represent mean \pm SEM of values from three determinations. (c) Western blot assays on proteins precipitated from the MSC-CdM and CF-CdM. Representative of three independent experiments. ${ }^{* *} P<0.01$.

by $45.7 \%$ after reoxygenation injury, which was absent when treated with the conditioned medium derived from MSCs that transfected shRNA lentivirus targeting HDGF. Being consistent with PI-Annexin V double staining, MSC ${ }^{\text {null }}$ $\mathrm{CdM}$ significantly attenuated $(P<0.05)$ reoxygenationinduced activation of caspase-3 in H9C2 cells (Figure 3(b)). In contrast, knockdown of HDGF in MSCs impaired $(P<0.05)$ the MSC-CdM-mediated inhibitive effects on caspase-3 activation.

3.4. HDGF Reduced Apoptosis and Activated PKCE Pathway. To further validate the direct protective effects of HDGF on reperfusion injury, we applied mouse HDGF recombinant protein (100 nmol/L, Novoprotein Scientific, NJ, USA) or PBS as vehicle (Veh) to H9C2 cells that were subjected to $\mathrm{H} / \mathrm{R}$ injury. $\mathrm{PI}-\mathrm{Ann}$ exin $\mathrm{V}$ double positive population was reduced by $29.2 \%$ when treated with HDGF recombinant protein (Figure 4(a)). In addition, a decrease in percentage of Annexin $\mathrm{V}$ positive and low PI cell population (in Q4 quadrant) was observed, suggesting that HDGF protected against reperfusion-induced early stage apoptosis. We also performed immunoblotting assay to detect the activation of caspase- 3 and found that cleaved caspase- 3 was significantly reduced in the HDGF group, compared to the control (Figure 4(b)).

To explore the intracellular mechanisms underlying the protective effects of $\mathrm{HDGF}$, we examined $\mathrm{PKC} \varepsilon$ activity as this pathway has been proved to play essential roles in myocardial preconditioning and cytoprotection [20-23]. Our data showed that HDGF induced $\mathrm{PKC} \varepsilon$ phosphorylation (Figure 4(c)).Phosphorylated PKCe has been shown to translocate into mitochondria and interacts with ALDH2 contributing to 4-HNE detoxification during reperfusion injury [24]. Therefore, we assessed ALDH2 activity in myocardial mitochondria and 4-HNE which could reflect whether PKCE has been activated by HDGF. Our data showed that the delivery of recombinant HDGF significantly enhanced the activity of ALDH2 in mitochondria $(P<0.05)$ (Figure $4(\mathrm{~d}))$ and prevented 4-HNE accumulation (Figure 4(e)), compared with the control group. Thus, these data support the notion that HDGF reduced reoxygenation-induced oxidative stress through $\mathrm{PKC} \varepsilon$ activation.

\subsection{PKCe Played a Key Role in HDGF-Mediated Protection} against Reperfusion Injury. To further determine the role of $\mathrm{PKC} \varepsilon$ in HDGF-mediated protection in vivo, recombinant mouse HDGF $(50 \mu \mathrm{g} / \mathrm{kg}$ ) or PBS (as vehicle) was administered intramyocardially to both $\mathrm{PKC}-\mathrm{DN}$ mice and $\mathrm{WT}$ littermate (as controls). Administration of recombinant HDGF reduced I/AAR to $33.8 \pm 3.1 \%(P<0.05)$, compared to $44.9 \pm 2.6 \%$ in the control group (Figure $5(\mathrm{a})$ ). However, this reduction in infarct size by HDGF delivery was absent in $\mathrm{PKC} \varepsilon-\mathrm{DN}$ mice that had similar I/AAR to those without HDGF intervention, although the I/AAR was similar between $\mathrm{PKC} \varepsilon-\mathrm{DN}$ and WT mice, and AAR/LV in all groups had no significant difference. In addition, recombinant HDGF markedly increased $+\mathrm{dp}^{-\mathrm{dt}_{\max }}$ and $-\mathrm{dp} / \mathrm{dt}_{\max }$ at $24 \mathrm{~h}$ reperfusion in WT mice $(P<0.05)$ (Figure 5(b) and Supplementary Table 2). Although the mean value of $+\mathrm{dp} /$ $\mathrm{dt}_{\max }$ and $-\mathrm{dp} / \mathrm{dt}_{\max }$ in $\mathrm{PKC} \varepsilon-\mathrm{DN}$ mice was increased by HDGF treatment, the HDGF-mediated improvement of hemodynamic performance was significantly limited compared to that in WT $(P<0.05)$.

Being consistent with the infarct size quantification, administration of recombinant HDGF significantly decreased TUNEL positive myocytes $(P<0.05)$ in the periinfarct area in WT mice, which was not observed in PKC $\varepsilon$ DN mice (Figure 5(c)). Meanwhile, we detected an enhanced mitochondrial ALDH2 activity (Figure 5(d)) and a significant reduction in 4-HNE accumulation (Figure 5(e)) in reperfusion-injured myocardium of WT mice, but not in that of PKC $\varepsilon$-DN mice.

Moreover, HDGF enhanced contractile performance (Supplementary Fig. S3A, B) and upregulated calcium 
TABLE 1: Functional classification of the highly secreted protein identified in MSC-CdM.

\begin{tabular}{|c|c|c|}
\hline GO classification & Gene & Protein \\
\hline ADP catabolic process & NUDT9 & ADP-ribose pyrophosphatase, mitochondrial \\
\hline \multirow{3}{*}{ Apoptotic process } & HINT1 & Histidine triad nucleotide-binding protein 1 \\
\hline & NME1 & Nucleoside diphosphate kinase A \\
\hline & NME2 & Nucleoside diphosphate kinase B \\
\hline Biological process & OAF & Out at first protein homolog \\
\hline \multirow{6}{*}{ Biosynthetic process } & HRT1 & Hypoxanthine-guanine phosphoribosyltransferase \\
\hline & $\mathrm{ADA}$ & Adenosine deaminase \\
\hline & EEF1A1 & Elongation factor 1-alpha 1 \\
\hline & TPI1 & Triosephosphate isomerase \\
\hline & PGAM1 & Phosphoglycerate mutase 1 \\
\hline & EIF2S3X & Eukaryotic translation initiation factor 2 subunit 3 , X-linked \\
\hline Catabolic process & GSTO1 & Glutathione S-transferase omega-1 \\
\hline Cell adhesion & SPP1 & Osteopontin \\
\hline Cell cycle & PIN4 & Peptidyl-prolyl cis-trans isomerase NIMA-interacting 4 \\
\hline \multirow{2}{*}{ Cell differentiation } & TPT1 & Translationally controlled tumor protein \\
\hline & STMN1 & Stathmin \\
\hline Cell growth & MTPN & Myotrophin \\
\hline Cell morphogenesis & SMARCA4 & Transcription activator BRG1 \\
\hline Cell motility & BRK1 & Protein BRICK1 \\
\hline Cell-cell signaling & HDGF & Hepatoma-derived growth factor \\
\hline \multirow{3}{*}{ Cellular component morphogenesis } & CFL1 & Cofilin-1 \\
\hline & TUBA4A & Tubulin alpha- $4 \mathrm{~A}$ chain \\
\hline & SAA3 & Serum amyloid A-3 protein \\
\hline \multirow{4}{*}{ Cellular process } & SOD3 & Extracellular superoxide dismutase $[\mathrm{Cu}-\mathrm{Zn}]$ \\
\hline & LCN2 & Neutrophil gelatinase-associated lipocalin \\
\hline & NAMPT & Nicotinamide phosphoribosyltransferase \\
\hline & UCHL3 & Ubiquitin carboxyl-terminal hydrolase isozyme L3 \\
\hline DNA replication & PCNA & Proliferating cell nuclear antigen \\
\hline Endothelial cell proliferation & HMGB1 & High mobility group protein $\mathrm{B} 1$ \\
\hline Fatty acid catabolic process & ACOT7 & Cytosolic acyl coenzyme A thioester hydrolase \\
\hline \multirow{4}{*}{ Glycolysis } & LDHA & L-lactate dehydrogenase A chain \\
\hline & PGK1 & Phosphoglycerate kinase 1 \\
\hline & GAPDH & Glyceraldehyde-3-phosphate dehydrogenase \\
\hline & ENO1 & Alpha-enolase \\
\hline \multirow{2}{*}{ G-protein coupled receptor signaling pathway } & CXCL5 & C-X-C motif chemokine 5 \\
\hline & CCL8 & C-C motif chemokine 8 \\
\hline \multirow{3}{*}{ Immune system process } & HMGB2 & High mobility group protein $\mathrm{B} 2$ \\
\hline & MIF & Macrophage migration inhibitory factor \\
\hline & PSMA1 & Proteasome subunit alpha type-1 \\
\hline Metabolic process & PKM & Pyruvate kinase PKM \\
\hline Monosaccharide metabolic process & GALM & Aldose 1-epimerase \\
\hline \multirow{2}{*}{ Oxidation-reduction process } & AKR1B1 & Aldose reductase \\
\hline & AKR1B8 & Aldose reductase-related protein 2 \\
\hline Pentose phosphate shunt & PGLS & 6-phosphogluconolactonase \\
\hline \multirow{3}{*}{ Protein folding } & HSP90AA1 & Heat shock protein HSP 90 -alpha \\
\hline & HSP90AB1 & Heat shock protein HSP 90-beta \\
\hline & ST13 & Hsc70-interacting protein \\
\hline
\end{tabular}


TABLE 1: Continued.

\begin{tabular}{lcc}
\hline GO classification & Gene & Protein \\
\hline Protein metabolic process & LAP3 & Cytosol aminopeptidase \\
\hline Regulation of biological process & IGFBP6 & Insulin-like growth factor-binding protein 6 \\
\hline Response to oxidative stress & PRDX5 & Peroxiredoxin-5, mitochondrial \\
\hline & PTBP1 & Polypyrimidine tract-binding protein 1 \\
RNA splicing & PCBP1 & Poly(rC)-binding protein 1 \\
& SFPQ & Splicing factor, proline- and glutamine-rich \\
\hline Translation & RPS20 & 40S ribosomal protein S20 \\
\hline Carbohydrate metabolic process & GLO1 & Lactoylglutathione lyase
\end{tabular}

GO: Gene Ontology.
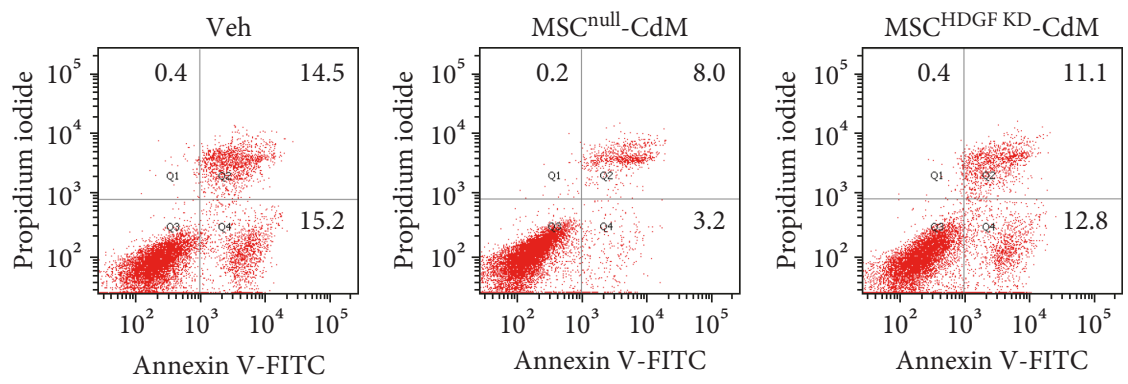

(a)

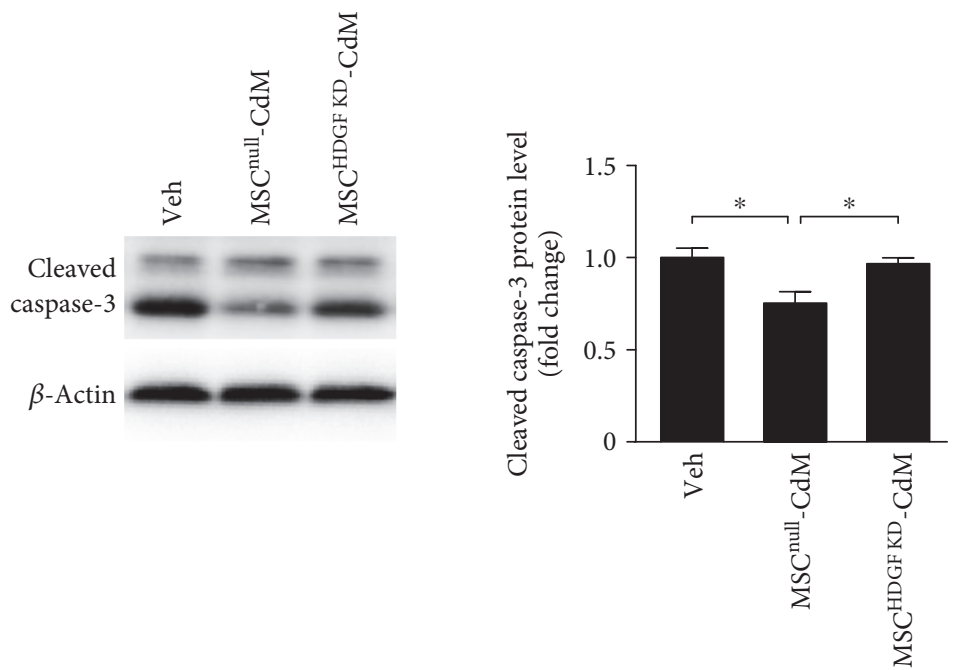

(b)

FIGURE 3: HDGF contributed to the protective effects of MSC-CdM. Conditioned medium that collected from MSCs transfected with vector $\left(\right.$ MSC $\left.^{\text {null }}-\mathrm{CdM}\right)$ or HDGF shRNA lentivirus (MSC ${ }^{\mathrm{HDGF} \text { KD }}$-CdM) were treated to H9C2 cells subjected to $9 \mathrm{~h}$ of hypoxia followed by $4 \mathrm{~h}$ of reoxygenation. (a) Cell death was evaluated with flow cytometry analysis. Annexin V-/PI-: viable cells; Annexin V+/PI-: early apoptotic cells; Annexin V+/PI+: late apoptotic or necrotic cells; Annexin V-/PI+: necrotic cells. (b) Cleaved caspases-3 as detected by Western blotting. Data represent mean \pm SEM of values from three determinations. ${ }^{*} P<0.05$.

transient amplitude (Supplementary Fig. S3C, D) in myocytes isolated from both WT and PKC $\mathrm{P}-\mathrm{DN}$ mice. This set of data could account for the improved hemodynamic performance in HDGF-treated $\mathrm{PKC}$-DN mice but also imply that additional mechanisms might be involved in HDGF-induced function recovery.

\section{Discussion}

In the present study, we have demonstrated that the conditioned medium derived from MSCs could exert cardioprotection. Through an iTRAQ-based proteomic analysis of the secretion from MSCs and CFs, we identified 


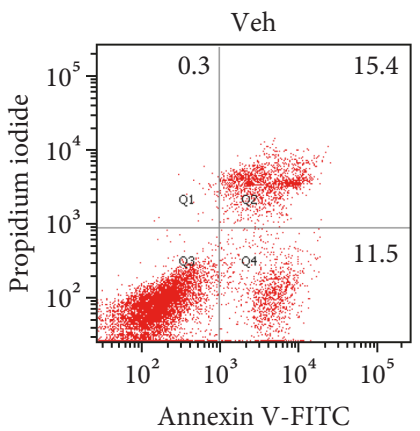

(a)
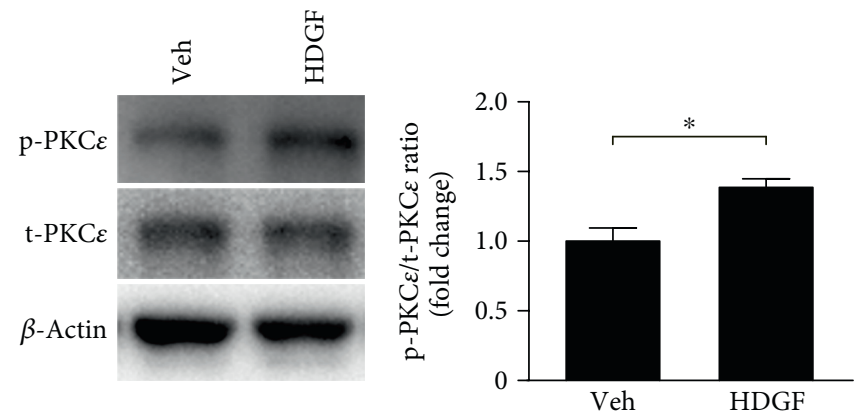

(c)
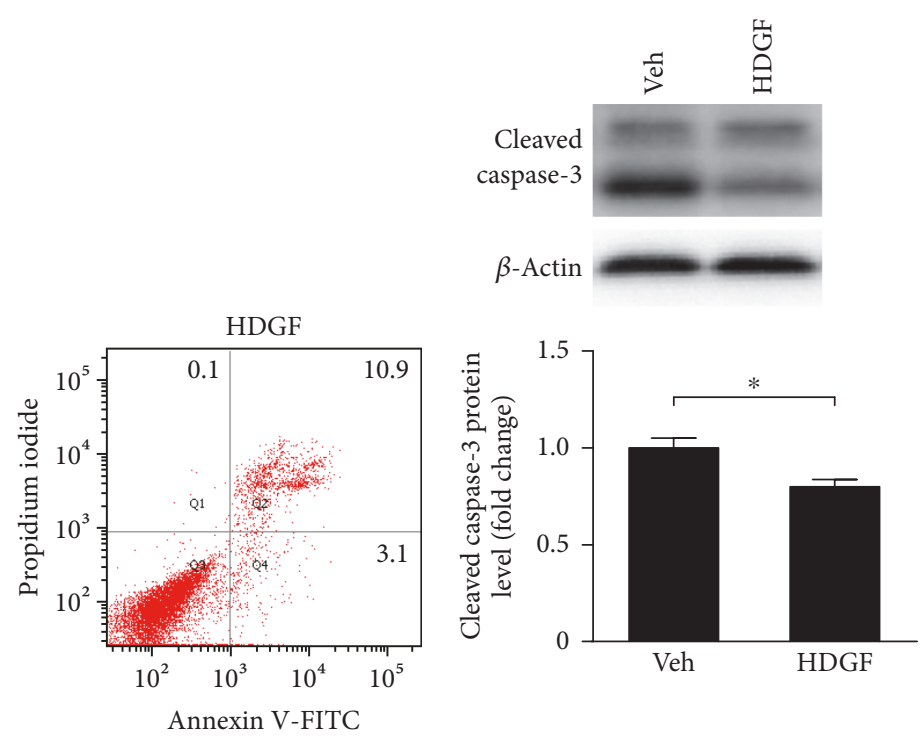

(b)

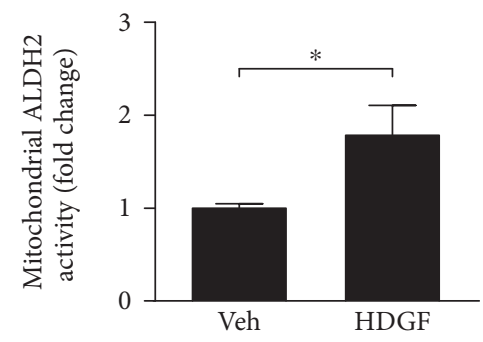

(d)
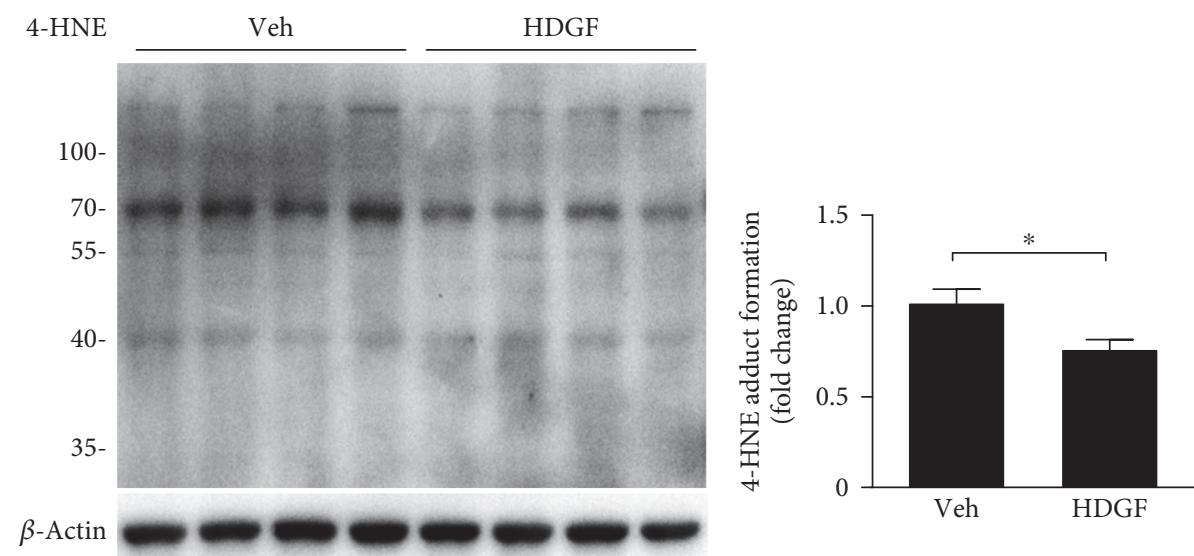

(e)

FIGURE 4: HDGF reduced apoptosis and activated PKC $\varepsilon$ pathway. H9C2 cells treated by recombinant mouse HDGF (100 nmol/L) or vehicle control were subjected to $9 \mathrm{~h}$ of hypoxia followed by $4 \mathrm{~h}$ of reoxygenation. (a) Cell death was evaluated with flow cytometry analysis. (b) Cleaved caspases -3 as detected by Western blotting. Data represent mean \pm SEM of values from three determinations. (c) Phosphorylation of PKC $\varepsilon$ as detected by Western blotting. Data represent mean \pm SEM of values from three determinations. (d) Mitochondria were isolated from $\mathrm{H} 9 \mathrm{C} 2$ cells and activity of $\mathrm{ALDH} 2$ in mitochondria was measured. Data represent mean \pm SEM of values from three mice. (e) 4-HNE protein adducts in H9C2 cells were assessed. Data represent mean \pm SEM of values from four determinations. ${ }^{*} P<0.05$. 

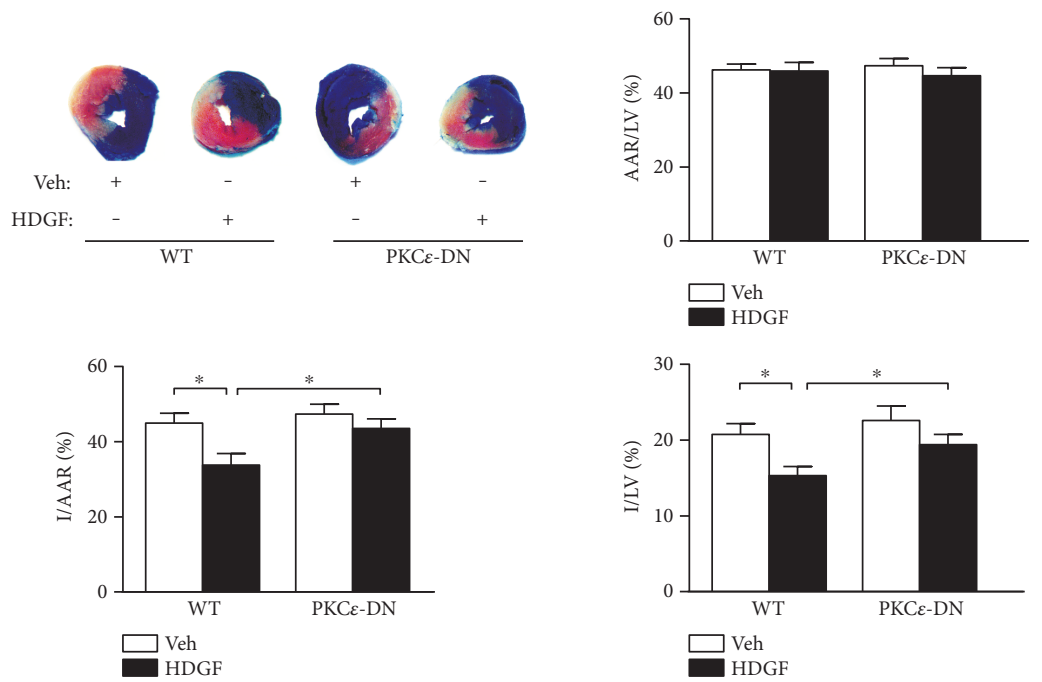

(a)

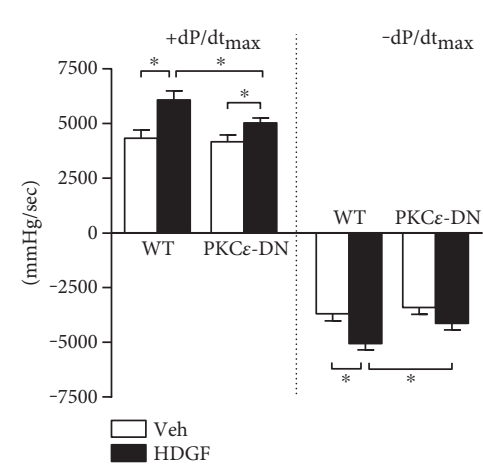

(b)

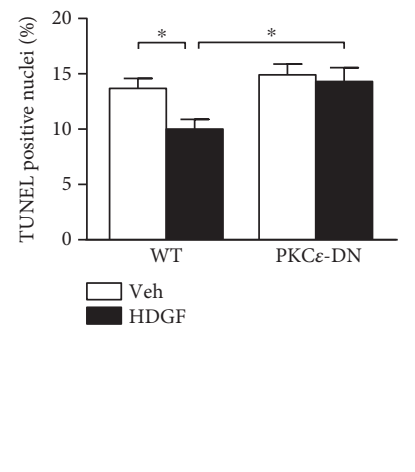

(c)
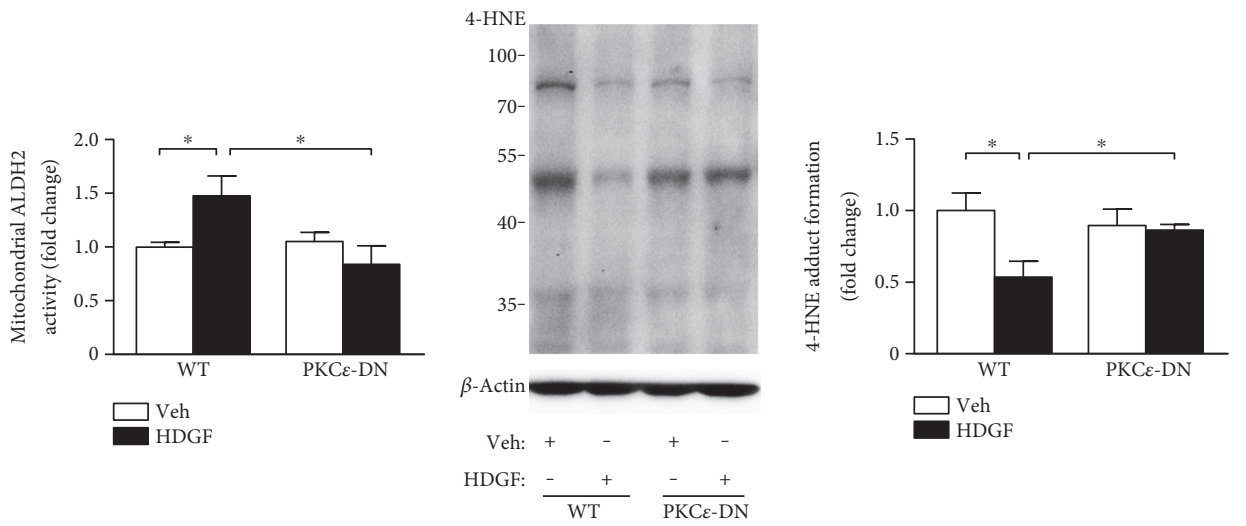

(d)

(e)

FIGURE 5: PKC $\varepsilon$ contributed to HDGF-induced reduction of reperfusion injury. PKCe dominant negative mice (PKCe-DN) and wild-type (WT) littermates with or without $50 \mu \mathrm{g} / \mathrm{kg}$ recombinant mouse HDGF treatment intramyocardially were subjected to $45 \mathrm{~min}$ of cardiac ischemia followed by $24 \mathrm{~h}$ reperfusion. (a) Ratio of area at risk to left ventricle area (AAR/LV), ratio infarct size to AAR ratio (I/AAR), and ratio of infarct size to LV area (I/LV) of hearts were assessed. Data represent mean \pm SEM of values from five mice. (b) The maximum rates of rise and decline of left-ventricular pressure $\left(+\mathrm{dp} / \mathrm{dt}_{\max }\right.$ and $\left.-\mathrm{dp} / \mathrm{dt}_{\max }\right)$ assessed at $24 \mathrm{~h}$ reperfusion. Data are mean $\pm \mathrm{SEM}$ of values from six mice. (c) Quantitative analysis of TUNEL positive cells at $24 \mathrm{~h}$ reperfusion. Data are mean \pm SEM of values from three hearts per group, with at least 3000 nuclei examined per heart. (d) Mitochondria were isolated from heart tissue after reperfusion injury and the activity of ALDH2 in mitochondria was measured. Data represent mean \pm SEM of values from three mice. (e) 4-HNE protein adducts in heart tissues was assessed. Data represent mean \pm SEM of values from three mice. ${ }^{*} P<0.05$. 
HDGF as an important component that played an essential role in the prosurvival effects offered by MSC therapy. Administration of recombinant HDGF alone recapitulated MSC-mediated protection, resulting in a reduction in infarct size, decreased apoptosis, and improved cardiac function through $\mathrm{PKC} \varepsilon$ pathway.

Although CFs secrete paracrine factors such as FGF-1, FGF-2, IL-33, and tissue inhibitory metalloproteinases (TIMPs) that are beneficial to cardioprotection $[25,26]$, limited effects of CF-CdM were observed in our study. MSCs have been reported to secrete some distinct cytokines compared to dermal fibroblasts, which allow MSC therapy to exhibit superiority over fibroblasts therapy in the wound healing process $[27,28]$. As MSCs hold great promise for cell-based therapy, the identification of secreted factors along with the related underlying mechanisms is of great biological and therapeutic importance. We, for the first time, applied iTRAQ-based proteomics analysis to compare the secretion from MSCs and CFs. A list of secreted factors specifically highly expressed by MSCs was defined, among which HDGF was further investigated and proved to induce myocardial protection. Thus, we provided a feasible approach to identify protective factors in the secretions from MSCs. Of note, hypoxia can improve the paracrine effects of different types of cells. The conditioned medium from hypoxia-preconditioned CFs was reported to be able to induce protection for reperfusion-injured myocardium [29], which was not observed in our study when the conditioned medium was collected under normoxic condition. Our previous studies demonstrated that hypoxia preconditioning enhanced biological function and cardioprotective effects of MSCs in rodent and primate models of permanent myocardial ischemia $[10,11]$. Therefore, it remains to be further investigated whether hypoxic preconditioning enhances MSC protection against reperfusion injury and triggers MSC secretome alterations.

PKCE is one of the central players in protection induced by ischemic preconditioning [20, 21], which is considered as the most efficient way to prevent reperfusion injury [30]. Activation of PKCe induces its translocation to the mitochondria and triggers a variety of mechanisms to induce antiapoptotic and antinecrotic effects, including enhancement of ALDH2 activity which detoxifies ROSgenerated 4-HNE $[20,24]$, interaction with cytochrome $c$ oxidase subunit IV [31], inhibition of mitochondrial permeability transition pore (mPTP) opening [32], and stabilization of mitochondrial membrane potential $(\Delta \psi \mathrm{m})$. PKC $\varepsilon$ is known to be activated during reperfusion injury. However, the extent of $\mathrm{PKC} \varepsilon$ activation by reperfusion may be insufficient to induce significant cardioprotection, since there is no difference in cardiac function and infarct sizes between WT and $\mathrm{PKC} \varepsilon$ knockout mice $[33,34]$. Further deterioration was neither observed in $\mathrm{PKC} \varepsilon-\mathrm{DN}$ mice in our study. On the other hand, deletion of $\mathrm{PKC} \varepsilon$ can abolish ischemic preconditioning-mediated protection $[34,35]$, indicating that $\mathrm{PKC} \varepsilon$ is indispensable and might be further enhanced to take part in the protection against reperfusion injury. In this regard, identifying agents, such as HDGF that stimulates the $\mathrm{PKC} \varepsilon$ pathway, will be of therapeutic benefit. Our data indicates that HDGF activates $\mathrm{PKC} \varepsilon$ and induces a $\mathrm{PKC} \varepsilon$ dependent protection, including suppression of apoptosis, limitation of reperfusion-induced oxidative stress, and reduction in infarct size.

It has to be born in mind though that $\mathrm{PKC} \varepsilon$ may not be the sole pathway involved in HDGF-mediated protection, since HDGF-induced effects on myocyte contractility and calcium handling were not impaired when PKCE was disrupted. In addition, we utilized isolated adult cardiomyocytes to detect myocyte calcium cycling and contractility in the present study. The H9C2 cell line was also used, due to the ease of handling as well as the ethical issues of laboratory animal use without significantly compromising the mechanistic molecular experiment. However, it is a cloned embryonic cardiac myoblast cell line obtained from embryonic rat heart, which does not truly possess morphological characteristics of matured cardiomyocytes.

HDGF was originally isolated from the conditioned medium of hepatoma-derived cells as a heparin-binding growth factor, and its role in the development of cardiovascular tissues was proved afterwards [36]. Over the last two decades, HDGF has been reported to be involved in many biological processes, such as wound repair [37], angiogenesis [38], and antiapoptosis [39]. Downregulation of HDGF impairs activation of certain survival pathways, leading to the cellular apoptosis under stress $[18,39]$. Therefore, HDGF may function as an antiapoptotic factor underlying the protection of MSCs. In this study, knockdown of HDGF impaired the effects of MSCs, indicating that HDGF plays an important role in MSC protection. HDGF also can improve proliferation [16] and migration [40], both of which are important processes in cardiac repair and regeneration. Administration of recombinant HDGF has been shown to induce a reduction in infarct size and improved cardiac function, suggesting that HDGF can be of great clinical benefit in the prevention of reperfusion injury.

\section{Abbreviations}

HDGF: Hepatoma-derived growth factor

MSC: $\quad$ Mesenchymal stem cell

CF: $\quad$ Cardiac fibroblast

CdM: $\quad$ Conditioned medium

PKCe: $\quad$ Protein kinase $C$ epsilon

WT: Wild type

PKC $\varepsilon$-DN: $\mathrm{PKC} \varepsilon$ dominant negative

4-HNE: 4-hydroxy-2-nonenal

ALDH2: Aldehyde dehydrogenase family 2

KD: Knockdown.

\section{Conflicts of Interest}

None of the authors has any conflicts of interest to disclose relevant to this work.

\section{Acknowledgments}

The authors thank Professor Peipei Ping for the kind gift of PKC epsilon-dominant negative transgenic mice, and 
Dr. Hong Lu and Professor Keith A. Webster for their critical input on this manuscript. This work was supported by the National High-tech R\&D 863 Program (no. 2013AA020101), the National Basic Research Program of China (973 Program nos. 2014CB965100 and 2014CB965103), grants from the National Natural Science Foundation of China (nos. 31171418, 81320108003 and 31371498 for Jian-An Wang; nos. 81170308 and 81370247 for Xinyang Hu; no. 81573641 for Ling Zhang; no. 31271585 for Hong Yu; and no. 81370346 for Wei Zhu), the Science and Technology Department of Zhejiang Province public welfare projects (no. 2013C37054 for Xinyang $\mathrm{Hu}$ and no. 2014C33190 for Rongrong $\mathrm{Wu}$ ), and the Zhejiang Provincial Natural Science Foundation (no. LY16H280003 for Ling Zhang and no. 2013C24009 for Hong $\mathrm{Yu})$.

\section{References}

[1] V. L. Roger, A. S. Go, D. M. Lloyd-Jones et al., "Heart disease and stroke statistics-2012 update: a report from the American Heart Association," Circulation, vol. 125, pp. e2-e220, 2012.

[2] L. Wu, J. L. Tan, Z. H. Wang et al., "ROS generated during early reperfusion contribute to intermittent hypobaric hypoxia-afforded cardioprotection against postischemiainduced $\mathrm{Ca}^{2+}$ overload and contractile dysfunction via the JAK2/STAT3 pathway," Journal of Molecular and Cellular Cardiology, vol. 81, pp. 150-161, 2015.

[3] E. Lopez-Bernardo, A. Anedda, P. Sanchez-Perez, B. AcostaIborra, and S. Cadenas, "4-Hydroxynonenal induces Nrf2mediated UCP3 upregulation in mouse cardiomyocytes," Free Radical Biology \& Medicine, vol. 88, pp. 427-438, 2015.

[4] Y. C. Awasthi, K. V. Ramana, P. Chaudhary, S. K. Srivastava, and S. Awasthi, "Regulatory roles of glutathione-Stransferases and 4-hydroxynonenal in stress-mediated signaling and toxicity," Free Radical Biology \& Medicine, vol. 111, pp. 235-243, 2017.

[5] P. Eaton, J. M. Li, D. J. Hearse, and M. J. Shattock, "Formation of 4-hydroxy-2-nonenal-modified proteins in ischemic rat heart," The American Journal of Physiology, vol. 276, pp. H935-H943, 1999.

[6] S. T. Ji, H. Kim, J. Yun, J. S. Chung, and S. M. Kwon, "Promising therapeutic strategies for mesenchymal stem cell-based cardiovascular regeneration: from cell priming to tissue engineering," Stem Cells International, vol. 2017, Article ID 3945403, 13 pages, 2017.

[7] K. Tamama and D. J. Barbeau, "Early growth response genes signaling supports strong paracrine capability of mesenchymal stem cells," Stem Cells International, vol. 2012, Article ID 428403, 7 pages, 2012.

[8] X. Hu, P. Chen, Y. Wu et al., "MiR-211/STAT5A signaling modulates migration of mesenchymal stem cells to improve its therapeutic efficacy," Stem Cells, vol. 34, pp. 1846-1858, 2016.

[9] X. Hu, L. Zhang, J. Jin et al., "Heparanase released from mesenchymal stem cells activates integrin beta1/HIF-2alpha/ Flk-1 signaling and promotes endothelial cell migration and angiogenesis," Stem Cells, vol. 33, pp. 1850-1862, 2015.

[10] X. Hu, Y. Xu, Z. Zhong et al., "A large-scale investigation of hypoxia-preconditioned allogeneic mesenchymal stem cells for myocardial repair in nonhuman primates: paracrine activity without remuscularization," Circulation Research, vol. 118, pp. 970-983, 2016.

[11] P. Chen, R. Wu, W. Zhu et al., "Hypoxia preconditioned mesenchymal stem cells prevent cardiac fibroblast activation and collagen production via leptin," PLoS One, vol. 9, article e103587, 2014.

[12] X. Hu, R. Wu, Z. Jiang et al., "Leptin signaling is required for augmented therapeutic properties of mesenchymal stem cells conferred by hypoxia preconditioning," Stem Cells, vol. 32, no. 10, pp. 2702-2713, 2014.

[13] L. Timmers, S. K. Lim, I. E. Hoefer et al., "Human mesenchymal stem cell-conditioned medium improves cardiac function following myocardial infarction," Stem Cell Research, vol. 6, pp. 206-214, 2011.

[14] L. Timmers, S. K. Lim, F. Arslan et al., "Reduction of myocardial infarct size by human mesenchymal stem cell conditioned medium," Stem Cell Research, vol. 1, pp. 129137, 2007.

[15] C. P. Baines, J. Zhang, G.-W. Wang et al., "Mitochondrial $\mathrm{PKC} \varepsilon$ and MAPK form signaling modules in the murine heart: enhanced mitochondrial PKCE-MAPK interactions and differential MAPK activation in PKCE-induced cardioprotection," Circulation Research, vol. 90, pp. 390-397, 2002.

[16] M. Li, J. Shen, X. Wu et al., "Downregulated expression of hepatoma-derived growth factor (HDGF) reduces gallbladder cancer cell proliferation and invasion," Medical Oncology, vol. 30, p. 587, 2013.

[17] Y. Kishima, K. Yoshida, H. Enomoto et al., "Antisense oligonucleotides of hepatoma-derived growth factor (HDGF) suppress the proliferation of hepatoma cells," Hepato-Gastroenterology, vol. 49, pp. 1639-1644, 2002.

[18] S. S. Hsu, C. H. Chen, G. S. Liu et al., "Tumorigenesis and prognostic role of hepatoma-derived growth factor in human gliomas," Journal of Neuro-Oncology, vol. 107, pp. 101-109, 2012.

[19] Y. Yu, H. Shen, H. Yu et al., "Systematic proteomic analysis of human hepotacellular carcinoma cells reveals molecular pathways and networks involved in metastasis," Molecular BioSystems, vol. 7, pp. 1908-1916, 2011.

[20] G. R. Budas, E. N. Churchill, and D. Mochly-Rosen, "Cardioprotective mechanisms of $\mathrm{PKC}$ isozyme-selective activators and inhibitors in the treatment of ischemia-reperfusion injury," Pharmacological Research, vol. 55, pp. 523-536, 2007.

[21] H. Tong, W. Chen, C. Steenbergen, and E. Murphy, "Ischemic preconditioning activates phosphatidylinositol-3-kinase upstream of protein kinase C," Circulation Research, vol. 87, pp. 309-315, 2000.

[22] M. O. Gray, J. S. Karliner, and D. Mochly-Rosen, “A selective $\varepsilon$-protein kinase $\mathrm{C}$ antagonist inhibits protection of cardiac myocytes from hypoxia-induced cell death," Journal of Biological Chemistry, vol. 272, pp. 30945-30951, 1997.

[23] G. S. Liu, M. V. Cohen, D. Mochly-Rosen, and J. M. Downey, "Protein kinase C- $\xi$ is responsible for the protection of preconditioning in rabbit cardiomyocytes," Journal of Molecular and Cellular Cardiology, vol. 31, pp. 1937-1948, 1999.

[24] G. R. Budas, E. N. Churchill, M.-H. Disatnik, L. Sun, and D. Mochly-Rosen, "Mitochondrial import of PKCe is mediated by HSP90: a role in cardioprotection from ischaemia and reperfusion injury," Cardiovascular Research, vol. 88, pp. 83-92, 2010. 
[25] K. Seki, S. Sanada, A. Y. Kudinova et al., "Interleukin-33 prevents apoptosis and improves survival after experimental myocardial infarction through ST2 signaling," Circulation Heart Failure, vol. 2, pp. 684-691, 2009.

[26] Z. S. Jiang, G. B. Wen, Z. H. Tang, W. Srisakuldee, R. R. Fandrich, and E. Kardami, "High molecular weight FGF-2 promotes postconditioning-like cardioprotection linked to activation of protein kinase C isoforms, as well as Akt and p70 S6 kinases," Canadian Journal of Physiology and Pharmacology, vol. 87, pp. 798-804, 2009.

[27] L. Chen, E. E. Tredget, W. PY, and Y. Wu, "Paracrine factors of mesenchymal stem cells recruit macrophages and endothelial lineage cells and enhance wound healing," PLoS One, vol. 3, article e1886, 2008.

[28] S. Wang, H. Yang, Z. Tang, G. Long, and W. Huang, "Wound dressing model of human umbilical cord mesenchymal stem cells-alginates complex promotes skin wound healing by paracrine signaling," Stem Cells International, vol. 2016, Article ID 3269267, 8 pages, 2016.

[29] M. Abrial, C. C. Da Silva, B. Pillot et al., "Cardiac fibroblasts protect cardiomyocytes against lethal ischemia-reperfusion injury," Journal of Molecular and Cellular Cardiology, vol. 68, pp. 56-65, 2014.

[30] C. E. Murry, R. B. Jennings, and K. A. Reimer, "Preconditioning with ischemia: a delay of lethal cell injury in ischemic myocardium," Circulation, vol. 74, pp. 1124-1136, 1986.

[31] M. Ogbi and J. A. Johnson, "Protein kinase Ce interacts with cytochrome $c$ oxidase subunit IV and enhances cytochrome $c$ oxidase activity in neonatal cardiac myocyte preconditioning," The Biochemical Journal, vol. 393, pp. 191-199, 2006.

[32] C. P. Baines, C. X. Song, Y. T. Zheng et al., "Protein kinase $\mathrm{C} \varepsilon$ interacts with and inhibits the permeability transition pore in cardiac mitochondria," Circulation Research, vol. 92, pp. 873-880, 2003.

[33] M. O. Gray, H. Z. Zhou, I. Schafhalter-Zoppoth, P. Zhu, D. Mochly-Rosen, and R. O. Messing, "Preservation of base-line hemodynamic function and loss of inducible cardioprotection in adult mice lacking protein kinase $\mathrm{C} \varepsilon$," The Journal of Biological Chemistry, vol. 279, pp. 3596-3604, 2004.

[34] A. T. Saurin, D. J. Pennington, N. J. Raat, D. S. Latchman, M. J. Owen, and M. S. Marber, "Targeted disruption of the protein kinase $\mathrm{C}$ epsilon gene abolishes the infarct size reduction that follows ischaemic preconditioning of isolated buffer-perfused mouse hearts," Cardiovascular Research, vol. 55, pp. 672-680, 2002.

[35] P. Ping, H. Takano, J. Zhang et al., "Isoform-selective activation of protein kinase $\mathrm{C}$ by nitric oxide in the heart of conscious rabbits: a signaling mechanism for both nitric oxide-induced and ischemia-induced preconditioning," Circulation Research, vol. 84, pp. 587-604, 1999.

[36] A. D. Everett, "Identification, cloning, and developmental expression of hepatoma-derived growth factor in the developing rat heart," Developmental Dynamics, vol. 222, pp. 450-458, 2001.

[37] A. D. Everett, D. R. Lobe, M. E. Matsumura, H. Nakamura, and C. A. McNamara, "Hepatoma-derived growth factor stimulates smooth muscle cell growth and is expressed in vascular development," Journal of Clinical Investigation, vol. 105, pp. 567-575, 2000.

[38] A. D. Everett, J. V. Narron, T. Stoops, H. Nakamura, and A. Tucker, "Hepatoma-derived growth factor is a pulmonary endothelial cell-expressed angiogenic factor," American Journal of Physiology Lung Cellular and Molecular Physiology, vol. 286, pp. L1194-L1201, 2004.

[39] T. Y. Tsang, W. Y. Tang, W. P. Tsang, N. N. Co, S. K. Kong, and T. T. Kwok, "Downregulation of hepatoma-derived growth factor activates the Bad-mediated apoptotic pathway in human cancer cells," Apoptosis, vol. 13, pp. 1135-1147, 2008.

[40] C. H. Wang, F. Davamani, S. C. Sue et al., "Cell surface heparan sulfates mediate internalization of the PWWP/HATH domain of HDGF via macropinocytosis to fine-tune cell signalling processes involved in fibroblast cell migration," Biochemical Journal, vol. 433, pp. 127-138, 2011. 

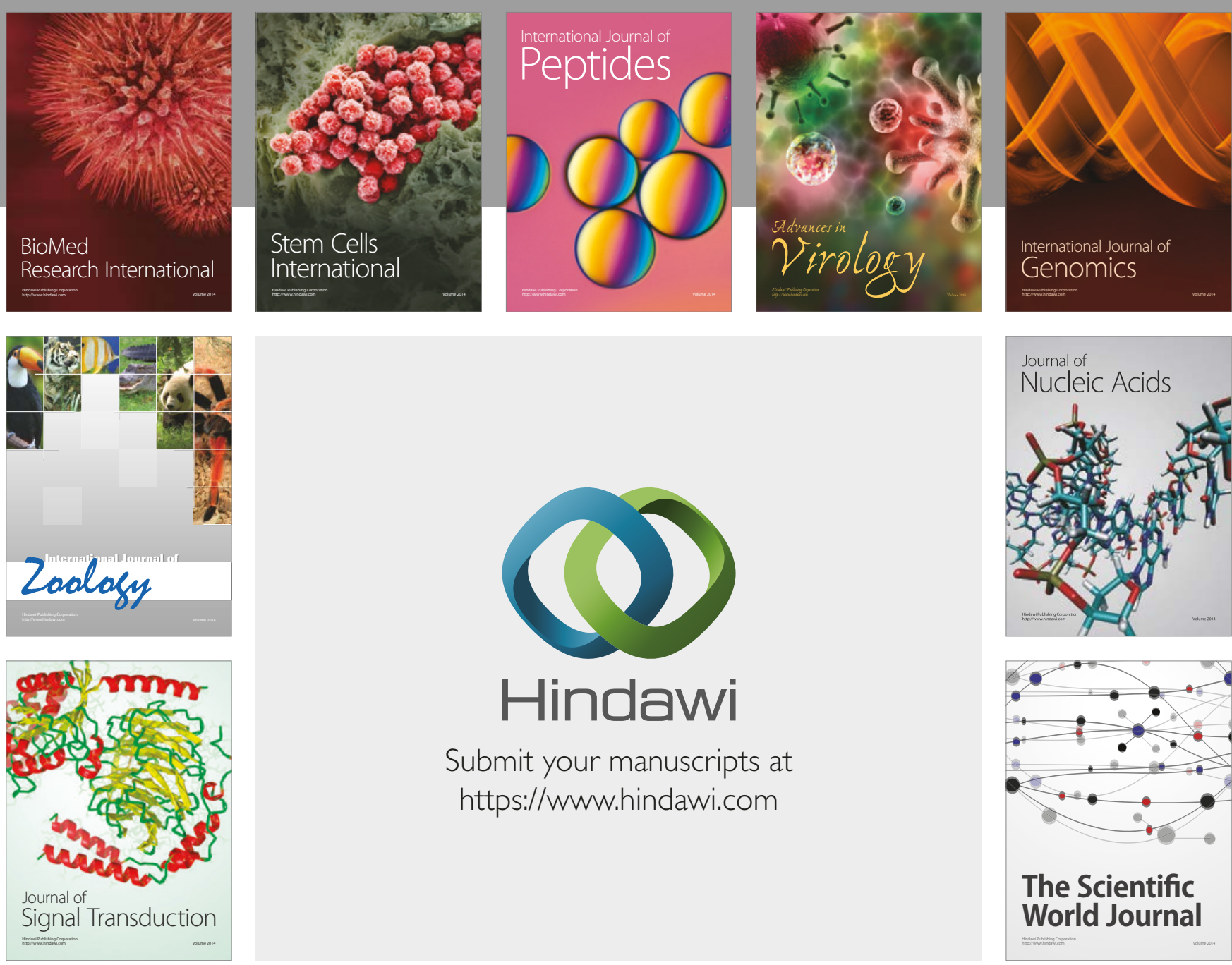

Submit your manuscripts at

https://www.hindawi.com
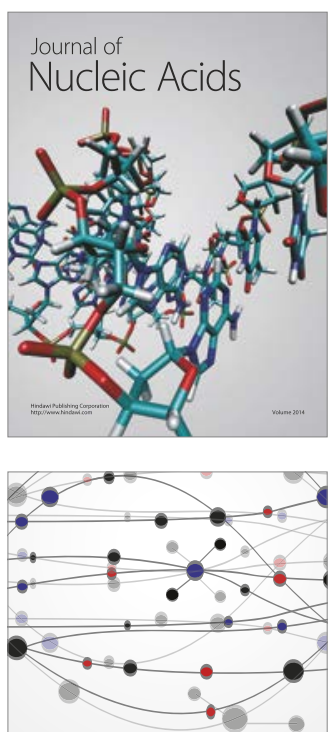

The Scientific World Journal

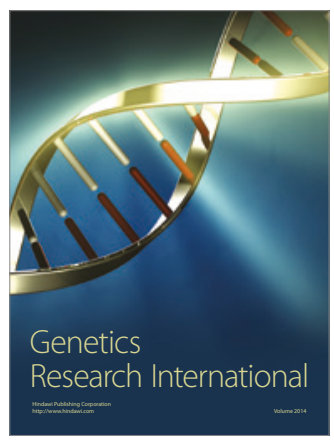

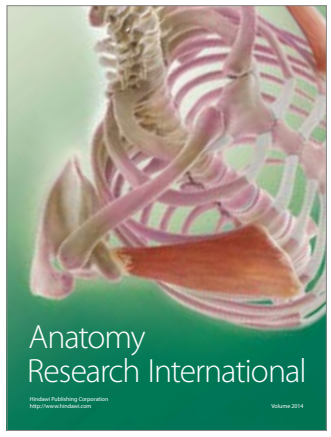

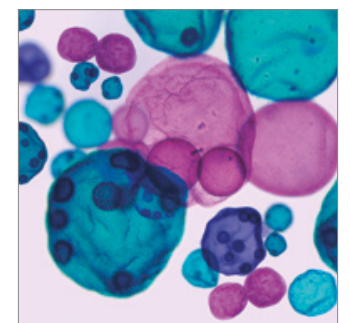

International Journal of Microbiology
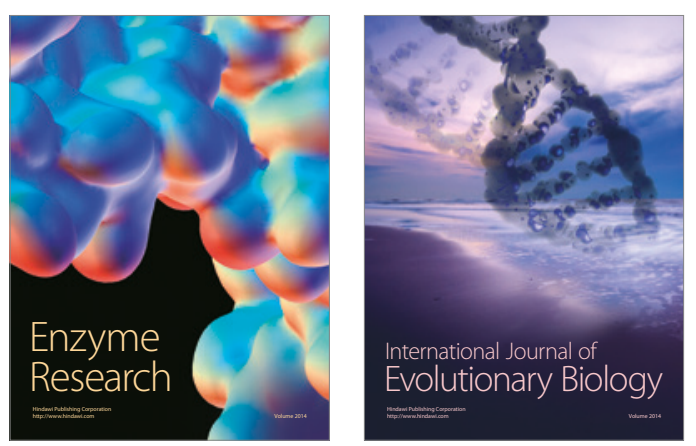
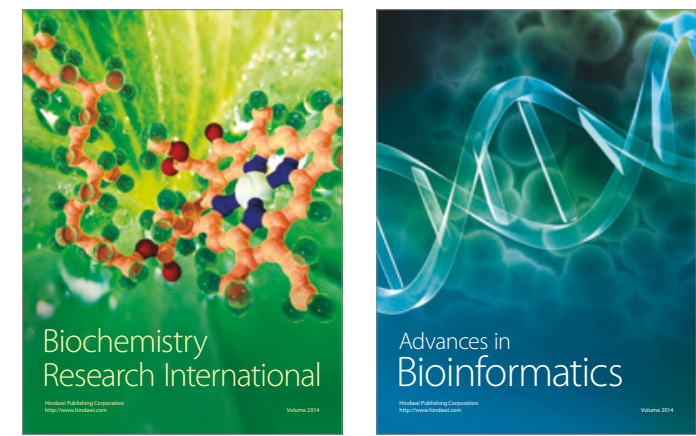

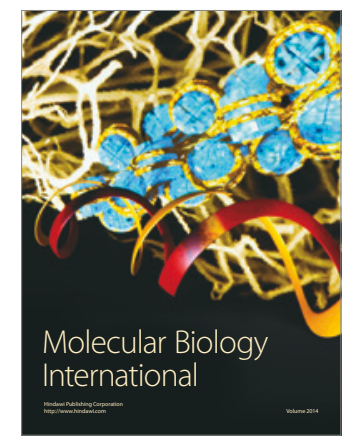

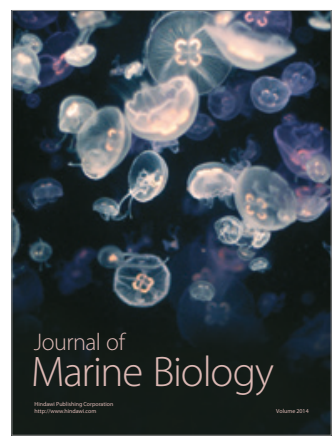

